\title{
A genetic framework for flowering-time pathways in Citrus spp.
}

\author{
Marcelo Carnier Dornelas ${ }^{1}$, Raquel Luciana Boscariol Camargo ${ }^{2}$, \\ Luciana Harumi Morimoto Figueiredo ${ }^{2}$ and Marco Aurélio Takita ${ }^{2}$ \\ ${ }^{1}$ Departamento de Fisiologia Vegetal, Instituto de Biologia, Universidade Estadual de Campinas, \\ Cidade Universitária Zeferino Vaz, Campinas,SP, Brazil. \\ ${ }^{2}$ Centro APTA Citrus Sylvio Moreira, Instituto Agronômico de Campinas, Cordeirópolis, SP, Brazil.
}

\begin{abstract}
Floral transition is one the most drastic changes occurring during the life cycle of a plant. The shoot apical meristem switches from the production of leaves with associated secondary shoot meristems to the production of flower meristems. This transition is abrupt and generally irreversible, suggesting it is regulated by a robust gene regulatory network capable of driving sharp transitions. The moment at which this transition occurs is precisely determined by environmental and endogenous signals. A large number of genes acting within these pathways have been cloned in model herbaceous plants such as Arabidopsis thaliana. In this paper, we report the results of our search in the Citrus expressed sequence tag (CitEST) database for expressed sequence tags (ESTs) showing sequence homology with known elements of flowering-time pathways. We have searched all sequence clusters in the CitEST database and identified more than one hundred Citrus spp sequences that codify putative conserved elements of the autonomous, vernalization, photoperiod response and gibberelic acid-controlled flowering-time pathways. Additionally, we have characterized in silico putative members of the Citrus spp homologs to the Arabidopsis CONSTANS family of transcription factors.
\end{abstract}

Key words: reproductive development, flowering-time genes, reproduction, photoperiod, CONSTANS.

Received: July 21, 2006; Accepted: April 2, 2007.

\section{Introduction}

When grown from seeds, Citrus seedlings progress through a developmental ontogeny typical for woody perennials, eventually producing a moderately sized tree. After a juvenile period, typically lasting several years, Citrus trees enter the adult phase in which they are capable of continuously producing flowers in addition to vegetative shoots (Krajewski and Rabe, 1995). Flowers can potentially be produced throughout the year, but in most oranges and mandarins grown in temperate environments, the majority of flowers are produced during the spring flush. Thousands of flowers are usually produced on established trees, but only a relatively small proportion develops into fruit. In some varieties, pollination, fertilization and seed development are required for fruit set, while in others, parthenocarpic fruit development can occur. In some cases this is stimulated by pollination (Koltunow et al., 2000).

For a given Citrus species and/or variety, the number of fruit on an individual tree is negatively correlated with final fruit size. Consequently, the tendency for Citrus to ex-

Send correspondence to Marcelo C. Dornelas. Departamento de Fisiologia Vegetal, Instituto de Biologia, Universidade Estadual de Campinas, Cidade Universitária Zeferino Vaz, Caixa Postal 6109, 13.083-970 Campinas, SP, Brazil. E-mail: dornelas@ unicamp.br. hibit a biennial bearing pattern of different flowering intensities has a significant impact on fruit size at harvest. In "on" years a relatively large number of flowers are produced (and thus small fruits), while in "off" years relatively few flowers are formed as well as fewer, but bigger fruits (Garcia-Luis et al., 1992; Garcia-Luis and Kanduser, 1995; Garcia-Luis et al., 1995). Because of this effect, trees of a particular variety within a geographical area tend to become synchronized in their biennial bearing pattern. While this simplifies management to some extent, it greatly exacerbates the overproduction of small fruit in "on" years. Thus, the understanding of the molecular regulation of the flowering process is crucial for controlling fruit production in Citrus.

The rapid advances made in understanding Arabidopsis flowering have allowed researchers to begin similar investigations in perennial crops. This knowledge is greatly accelerating flowering research in perennial trees because, at least in a general sense, the same genes appear to be involved in flower initiation, flower formation, and fruit development in all of the important flowering plants. Using the DNA sequence of flowering genes from model plants as a starting point, flowering genes have been successfully isolated from several agriculturally important tree 
crops, including apple (Yao et al., 1999; Sung et al., 1999; Sung et al., 2000; Kotoda et al., 2000), Citrus (Pillitteri et al., 2004), grape (Boss et al., 2001; Boss et al., 2002), and Eucalyptus (Kyozuka et al., 1997; Southerton et al., 1998; Dornelas et al., 2004; Dornelas and Rodriguez, 2005).

Here we concentrated on the characterization of genes involved in the pathways that lead to the transition from vegetative to reproductive development in Citrus species. With this goal, we have used the sequences of the key proteins of the different developmental pathways involved in the regulation of flowering-time available from Arabidopsis as bait to search the Citrus database of expressed sequence tags (CitEST) showing sequence homology with known elements of flowering-time pathways. Additionally, we have undertaken an extensive in silico characterization of the putative Citrus homologues of the CONSTANS gene family, which, in Arabidopsis, mediate the cross-talk between the circadian clock and the genes controlling reproductive meristem identity. We have identified Citrus sequences that codify putative conserved elements of the vernalization, photoperiod response, autonomous and gibberellic acid-controlled flowering-time pathways. We expect that our results will contribute to further studies describing how these pathways function in controlling the induction to flowering and thus the biennial fruit bearing pattern in Citrus.

\section{Material and Methods}

\section{Searching Citrus ESTs homologs to Arabidopsis flowering-time genes}

The overall goal of this study was to retrieve from the CitEST data set, Citrus spp homologs to all genes described to be involved in the control of flowering time, according to the processes showed in Figure 1. In order to achieve this, data mining in the CitEST database was carried out using published plant gene sequences as bait, as well as keyword searches in the CitEST home page (http://citest. centrodecitricultura.br/). Plant gene sequences used as bait were retrieved from public gene databases (http://www. ncbi.nlm.nih.gov/entrez/query.fcgi) using their corresponding accession numbers or by the use of keywordoriented searches (Mouradov et al., 2002; Izawa et al., 2003). Protein (deduced amino acid) sequences from the retrieved bait sequences were compared to Citrus spp clustered EST sequences using a combination of different Blast algorithms (Altschul et al., 1997), with the BLOSUM62 scoring matrix, with a threshold of $\mathrm{e}<10^{-10}$ for positive hits. The identity (in terms of donor cDNA library) and number of sequence read composition of each individual candidate cluster were checked to access their potential expression pattern.

For the results presented in Table 1, we have obtained e-values using the BLASTp algorithm (Altschul et al., 1997) as described above. The identity and the similarity

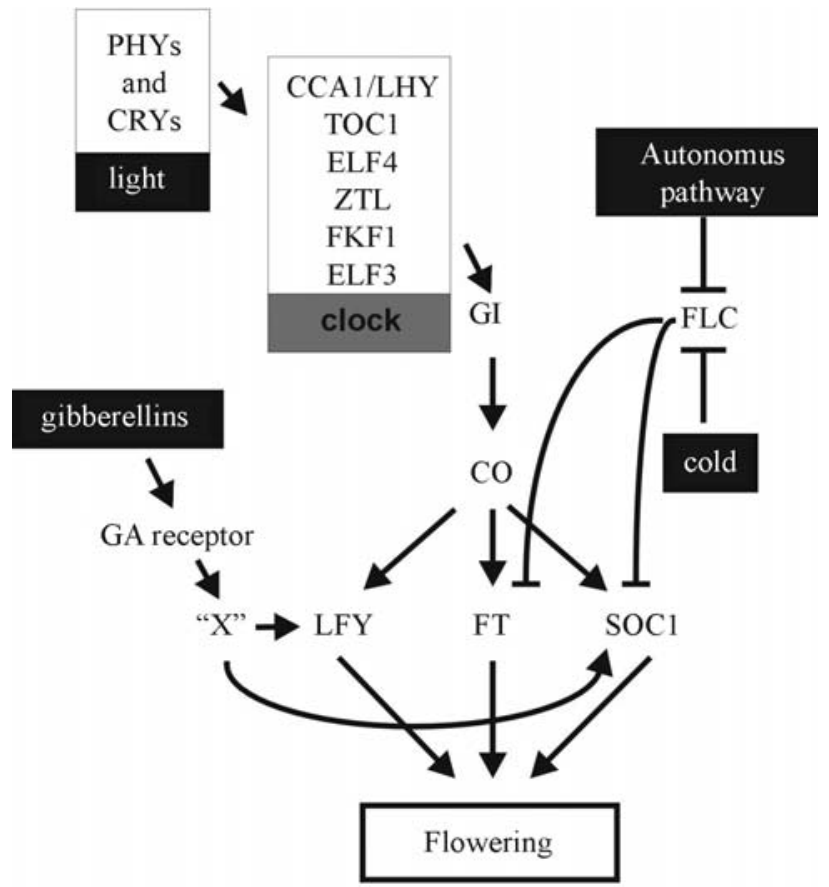

Figure 1 - Overview of the relationships among the elements involved in the flowering-time pathways in the model plant Arabidopsis thaliana (after Mouradov et al., 2002 and Izawa et al., 2003). The data underlying the model and the corresponding homologs in Citrus are presented in Table 1 and in the text. For abbreviations and gene names see Table 1.

were calculated at the amino acid level, relative to the corresponding Arabidopsis putative homolog, within the extension of the successful sequence alignment produced by their pair-wise comparison.

\section{In silico characterization of the Citrus homologs belonging to the CONSTANS gene family}

The Arabidopsis CONSTANS (CO) gene family codifies putative transcription factors defined by two conserved domains (Putterill et al., 1995; Griffiths et al., 2003). The first is a zinc finger region near the amino terminus that resembles B-boxes, which regulate protein-protein interactions in several animal transcription factors (Putterill et al., 1995). The second is a region of 43 amino acids near the carboxy terminus termed the CCT (CO, CO-like, TOC1) domain (Robson et al., 2001). We have identified Citrus homologs to the Arabidopsis $\mathrm{CO}$ gene family by using the Arabidopsis sequences as bait and the BLAST algorithms (Altschul et al., 1997) as described above. Only comparisons that produced an e-value better than $\mathrm{e}^{-50}$ were considered highly significant. In the cases where the obtained e-values were between $\mathrm{e}^{-50}$ and $\mathrm{e}^{-5}$, a re-clusterization of all reads identified was performed using the CAP3 algorithm from the BioEdit Software (Hall, 1999). The novel cluster consensus sequences obtained were re-submitted to BLAST and frequently better e-values were obtained. We analyzed these using the CDD algorithm (Marchler-Bauer et al., 2005) to identify the presence of conserved domains in the deduced protein sequence. 
Table 1 - Citrus ESTs that share homology to flowering-time genes of Arabidopsis.

\begin{tabular}{|c|c|c|c|c|c|c|}
\hline Category & Arabidopsis $^{a}$ & MIPS code & Citrus $^{\mathrm{b}}$ & e-value ${ }^{c}$ & $\mathrm{ID} / \mathrm{SIM}^{\mathrm{d}}$ & $\mathrm{ext}^{\mathrm{e}}$ \\
\hline \multirow[t]{13}{*}{ Photoreceptor } & \multirow[t]{3}{*}{ PHYA } & \multirow[t]{3}{*}{ At1g09570 } & CS00-C3-701-101-C11 & $6 e-86$ & $87 / 93$ & 70 \\
\hline & & & CR05-C3-701-030-B06 & $1 e-39$ & $55 / 65$ & 65 \\
\hline & & & CG32-C1-003-003-A11 & $4 e-32$ & $68 / 88$ & 66 \\
\hline & \multirow[t]{2}{*}{ PHYB } & \multirow[t]{2}{*}{ At2g18790 } & CS12-G8-000-003-D03 & $5 e-55$ & $62 / 78$ & 76 \\
\hline & & & CR05-C1-102-036-H07 & $4 e-64$ & $66 / 81$ & 62 \\
\hline & \multirow[t]{2}{*}{ PHYC } & \multirow[t]{2}{*}{ At5g35840 } & CS00-C3-705-056-G06 & $6 e-82$ & $67 / 83$ & 63 \\
\hline & & & CA26-C1-002-046-B05 & $4 e-38$ & $47 / 66$ & 68 \\
\hline & \multirow[t]{5}{*}{ CRY1 } & \multirow[t]{5}{*}{ At4g08920 } & CS00-C3-702-004-H06 & $1 \mathrm{e}-145$ & $90 / 94$ & 61 \\
\hline & & & CR05-C3-700-072-D08 & $1 \mathrm{e}-108$ & $75 / 85$ & 72 \\
\hline & & & CA26-C1-002-076-H02 & $2 \mathrm{e}-67$ & $82 / 91$ & 75 \\
\hline & & & PT11-C1-900-077-C09 & $1 \mathrm{e}-124$ & $86 / 94$ & 82 \\
\hline & & & LT33-C1-003-039-G09 & $3 e-18$ & $35 / 40$ & 52 \\
\hline & CRY2 & At1g04400 & CR05-C3-702-066-D11 & $1 \mathrm{e}-113$ & $77 / 89$ & 73 \\
\hline \multirow[t]{39}{*}{ Circadian clock } & \multirow[t]{5}{*}{ CCA1 } & \multirow[t]{5}{*}{ At2g46830 } & CS00-C3-702-052-G12 & $3 e-42$ & $71 / 98$ & 68 \\
\hline & & & CR05-C3-701-001-G09 & $4 e-32$ & $71 / 75$ & 62 \\
\hline & & & CG32-C1-003-066-G07 & $1 e-33$ & $64 / 65$ & 64 \\
\hline & & & CA26-C1-002-004-G09 & $3 e-29$ & $61 / 68$ & 65 \\
\hline & & & PT11-C1-900-096-C04 & $9 e-38$ & $72 / 74$ & 72 \\
\hline & \multirow[t]{5}{*}{ LHY } & \multirow[t]{5}{*}{ At1g01060 } & CS00-C1-650-038-E07 & $4 e-72$ & $86 / 88$ & 72 \\
\hline & & & CR05-C1-102-049-H08 & $2 \mathrm{e}-58$ & $85 / 87$ & 71 \\
\hline & & & CG32-C1-003-085-A11 & $6 e-47$ & $79 / 81$ & 65 \\
\hline & & & CA26-C1-002-004-G09 & $3 e-29$ & $74 / 80$ & 60 \\
\hline & & & PT11-C1-900-084-H09 & $2 e-67$ & $71 / 76$ & 59 \\
\hline & \multirow[t]{5}{*}{ GI } & \multirow[t]{5}{*}{ At1g22770 } & CS00-C3-705-019-F09 & $1 e-111$ & $88 / 89$ & 65 \\
\hline & & & CR05-C1-100-075-E08 & $1 \mathrm{e}-121$ & $84 / 87$ & 68 \\
\hline & & & CG32-C1-003-008-F10 & $1 e-105$ & $79 / 80$ & 78 \\
\hline & & & PT11-C1-900-095-D02 & $1 \mathrm{e}-44$ & $81 / 82$ & 87 \\
\hline & & & LT33-C1-003-095-A04 & $5 e-74$ & $66 / 75$ & 65 \\
\hline & \multirow[t]{6}{*}{ TOC1/APRR1 } & \multirow[t]{6}{*}{ At5g61380 } & $\mathrm{CS} 00-\mathrm{C} 3-702-097-\mathrm{G} 04$ & $2 \mathrm{e}-69$ & $78 / 85$ & 64 \\
\hline & & & Cr05-c1-100-016-f10 & $1 e-75$ & $77 / 78$ & 68 \\
\hline & & & CG32-C1-003-006-A02 & $2 \mathrm{e}-60$ & $64 / 68$ & 71 \\
\hline & & & CA26-C1-002-085-D04 & $3 e-36$ & $62 / 65$ & 70 \\
\hline & & & PT11-C1-901-054-G04 & $1 \mathrm{e}-76$ & $68 / 69$ & 69 \\
\hline & & & LT33-C1-003-021-B10 & $1 \mathrm{e}-28$ & $62 / 65$ & 69 \\
\hline & \multirow[t]{4}{*}{ ELF3 } & At2g25930 & CS00-C3-702-072-C10 & $6 e-10$ & $65 / 68$ & 65 \\
\hline & & & CR05-C1-100-007-E05 & $2 \mathrm{e}-20$ & $68 / 69$ & 65 \\
\hline & & & CA26-C1-002-082-B12 & $3 e-35$ & $56 / 64$ & 78 \\
\hline & & & PT11-C1-900-009-D09 & $1 \mathrm{e}-15$ & $55 / 57$ & 71 \\
\hline & ZTL & At5g57360 & CS00-C3-704-061-B11 & $1 \mathrm{e}-116$ & $84 / 85$ & 56 \\
\hline & & & CR05-C3-702-002-G04 & $1 e-103$ & $75 / 76$ & 65 \\
\hline & & & CL06-C4-500-040-H10 & $5 e-10$ & $75 / 79$ & 59 \\
\hline & & & CG32-C1-003-015-G02 & $1 \mathrm{e}-29$ & $78 / 79$ & 67 \\
\hline & & & CA26-C1-002-073-A02 & $4 \mathrm{e}-55$ & $69 / 71$ & 68 \\
\hline & & & PT11-C2-300-054-C06 & $1 \mathrm{e}-85$ & $72 / 80$ & 63 \\
\hline & & & LT33-C1-003-029-B10 & $1 \mathrm{e}-109$ & $76 / 82$ & 61 \\
\hline & LKP2 & At2g18910 & CS00-C3-704-061-B11 & $1 \mathrm{e}-85$ & $56 / 84$ & 59 \\
\hline & & & CR05-C3-702-002-G04 & $1 \mathrm{e}-103$ & $56 / 71$ & 72 \\
\hline & & & CL06-C4-500-040-H10 & $5 e-10$ & $46 / 56$ & 56 \\
\hline & & & CG32-C1-003-072-B01 & $1 e-116$ & $76 / 77$ & 70 \\
\hline & & & CA26-C1-002-015-B02 & $2 \mathrm{e}-96$ & $72 / 74$ & 64 \\
\hline & & & PT11-C2-300-054-C06 & $5 e-72$ & $76 / 79$ & 68 \\
\hline & & & LT33-C1-003-029-B10 & $1 \mathrm{e}-109$ & $66 / 68$ & 64 \\
\hline
\end{tabular}


Table 1 (cont.)

\begin{tabular}{|c|c|c|c|c|c|c|}
\hline Category & Arabidopsis $^{a}$ & MIPS code & Citrus $^{\mathrm{b}}$ & e-value ${ }^{c}$ & $\mathrm{ID} / \mathrm{SIM}^{\mathrm{d}}$ & $\mathrm{ext}^{\mathrm{e}}$ \\
\hline \multirow{9}{*}{$\begin{array}{l}\text { Circadian clock } \\
\text { mediator }\end{array}$} & \multirow[t]{3}{*}{ FKF1 } & \multirow[t]{3}{*}{ At1g68050 } & CS00-C1-102-053-E02 & $3 e-95$ & $68 / 78$ & 62 \\
\hline & & & CR05-C3-700-019-F11 & $7 e-62$ & $85 / 89$ & 64 \\
\hline & & & PT11-C1-900-027-F07 & $4 \mathrm{e}-10$ & $77 / 88$ & 62 \\
\hline & \multirow[t]{6}{*}{$\mathrm{CO}$} & \multirow[t]{6}{*}{ At5g15840 } & CS00-C1-100-086-A06 & $6 e-52$ & $75 / 78$ & 71 \\
\hline & & & CL06-C4-501-017-G07 & $1 \mathrm{e}-64$ & $74 / 76$ & 75 \\
\hline & & & CG32-C1-003-018-D09 & $1 e-66$ & $57 / 66$ & 70 \\
\hline & & & CA26-C1-002-061-D07 & $2 \mathrm{e}-63$ & $52 / 64$ & 69 \\
\hline & & & LT33-C1-003-096-C01 & $2 \mathrm{e}-20$ & $53 / 65$ & 64 \\
\hline & & & PT11-C1-901-085-G05 & $2 e-64$ & $55 / 62$ & 66 \\
\hline \multirow{10}{*}{$\begin{array}{l}\text { Floral pathway } \\
\text { integrator }\end{array}$} & \multirow[t]{3}{*}{ FT } & \multirow[t]{3}{*}{ At1g65480 } & CS00-C3-704-020-B11 & $5 e-54$ & $68 / 74$ & 68 \\
\hline & & & CL06-C4-501-024-H01 & $1 \mathrm{e}-17$ & $61 / 64$ & 64 \\
\hline & & & PT11-C9-005-004-G03 & $1 \mathrm{e}-28$ & $71 / 72$ & 63 \\
\hline & LFY & At5g61850 & not found (see text) & & & \\
\hline & \multirow[t]{6}{*}{$\mathrm{SOC} 1$} & \multirow[t]{6}{*}{ At2g45660 } & CS00-C3-705-050-G08 & $1 \mathrm{e}-59$ & $65 / 68$ & 67 \\
\hline & & & CR05-C3-700-098-B05 & $7 e-92$ & $63 / 64$ & 65 \\
\hline & & & CG32-C1-003-007-A12 & $9 e-96$ & $69 / 70$ & 66 \\
\hline & & & CA26-C1-002-079-C12 & $3 e-87$ & $69 / 71$ & 63 \\
\hline & & & PT11-C1-900-073-F02 & $2 \mathrm{e}-45$ & $67 / 69$ & 64 \\
\hline & & & LT33-C1-003-056-A03 & $2 \mathrm{e}-66$ & $65 / 67$ & 67 \\
\hline \multirow{6}{*}{$\begin{array}{l}\text { Vernalization } \\
\text { pathway }\end{array}$} & \multirow[t]{6}{*}{ FLC } & \multirow[t]{6}{*}{ At4g18280 } & CS00-C3-705-050-G08 & $9 e-96$ & $71 / 76$ & 69 \\
\hline & & & CR05-C3-700-098-B05 & $7 e-92$ & $82 / 86$ & 68 \\
\hline & & & CG32-C1-003-007-A12 & $1 \mathrm{e}-59$ & $82 / 94$ & 75 \\
\hline & & & CA26-C1-002-079-C12 & $2 \mathrm{e}-45$ & $85 / 94$ & 62 \\
\hline & & & PT11-C1-900-073-F02 & $3 e-87$ & $75 / 85$ & 69 \\
\hline & & & LT33-C1-003-056-A03 & $2 \mathrm{e}-66$ & $66 / 71$ & 65 \\
\hline \multirow[t]{11}{*}{ Chromatin-related } & \multirow[t]{5}{*}{ EMF2 } & \multirow[t]{5}{*}{ At5g51230 } & CS00-C3-703-014-A10 & $8 \mathrm{e}-34$ & $60 / 77$ & 62 \\
\hline & & & CR05-C3-702-101-D11 & $7 e-62$ & $64 / 71$ & 87 \\
\hline & & & CG32-C1-003-068-D09 & $3 e-23$ & $84 / 91$ & 94 \\
\hline & & & CA26-C1-002-103-B01 & $9 e-44$ & $54 / 67$ & 72 \\
\hline & & & PT11-C1-901-070-F02 & $6 e-59$ & $52 / 64$ & 66 \\
\hline & \multirow[t]{3}{*}{ FIE } & \multirow[t]{3}{*}{ At3g20740 } & $\mathrm{CS} 00-\mathrm{C} 3-703-047-\mathrm{A} 03$ & $2 \mathrm{e}-82$ & $74 / 82$ & 55 \\
\hline & & & CR05-C1-100-078-H01 & $1 \mathrm{e}-105$ & $66 / 79$ & 76 \\
\hline & & & CG32-C1-003-068-D09 & $3 e-23$ & $52 / 64$ & 66 \\
\hline & \multirow[t]{3}{*}{ LHP } & \multirow[t]{3}{*}{ At5g17690 } & CS00-C3-703-058-E10 & $4 \mathrm{e}-28$ & $42 / 54$ & 82 \\
\hline & & & CR05-C3-702-033-H07 & $7 e-16$ & $36 / 53$ & 83 \\
\hline & & & CA26-C1-002-100-G04 & $9 e-26$ & $83 / 89$ & 67 \\
\hline
\end{tabular}

aAbbreviations: APRR1: Arabidopsis PSEUDO RESPONSE REGULATOR1; CCA1: CIRCADIAN CLOCK ASSOCIATED 1; CK2: casein kinase2; CO: CONSTANS; CRY: CRYPTOCHROME; ELF3: EARLY FLOWERING3; EMF2: EMBRYONIC FLOWERING2; FIE: FERTILIZATION INDEPENDENT ENDOSPERM; FKF1: FLAVIN-BINDING, KELCH-REPEATS, F-BOX1; FLC: FLOWERING LOCUS C; FT: FLOWERING LOCUS T; LFY: LEAFY; LHP1: LIKE HETEROCHROMATIN PROTEIN1; LHY: LATE ELONGATED HYPOCOTYL; GI: GIGANTEA; PHY: PHYTOCHROME; SOC1: SUPPRESSOR OF OVEREXPRESSION OF CO1; TOC1: TIMING OF CAB EXPRESSION1.

${ }^{\mathrm{b}}$ Species identification code is CA: Citrus aurantium; CG: C. aurantifolia; CR: C. reticulata; CS: C. sinensis, LT: C. latifolia; PT: Poncirus trifoliata. ${ }^{c}$ Using the BLASTp algorithm (Altschul et al., 1997).

${ }^{\mathrm{d}} \mathrm{ID}=$ identity; SIM = similarity; both based on the amino acid sequence, relative to the putative Arabidopsis homologs.

${ }^{\mathrm{e}}$ ext $=$ extension of the successful alignment including eventual insertion/deletion events.

\section{Comparative and phylogenetic analysis of CONSTANS gene family homologs}

To examine the relationships between the Citrus CO-like genes and their putative Arabidopsis homologs in more detail, their nucleotide and predicted peptide sequences were used to determine genetic distances and to construct phylogenetic trees. Because the middle regions of the genes were the most divergent, they could not be aligned with confidence. Therefore, neighbor-joining (NJ) and maximum parsimony (MP) trees were constructed using B-box (and CCT domain sequences when available) following the alignments obtained using the CLUSTALX software (Thompson et al., 1994). The alignments were eventually corrected by hand. Phylogenetic trees were ob- 
tained using parsimony and/or genetic distance calculations. Neighbor-joining (Saitou and Nei, 1987) and Bootstrap (with 1000 replicates) trees were built using the MEGA software (http://www.megasoftware.net).

\section{Results}

\section{Identifying Citrus ESTs related to flowering-time pathway genes}

Genetic analyses in model plants such as Arabidopsis identified a whole set of flowering-time genes that were subsequently assigned to four major genetic pathways according to their response to the exposure of a period of cold (vernalization) or to day length (photoperiod) (Simpson et al., 1999; Araki, 2001; Mouradov et al., 2002; Simpson and Dean, 2002; Bastow and Dean, 2003; Amasino, 2004; Boss et al., 2004). The field of flowering time has thus been organized around these four pathways, with the photoperiod and vernalization pathways mediating the response to environmental cues and the autonomous and the gibberellin (GA) pathways acting largely independently of these external signals (Figure 1). Based on the systematic search in the CitEST database using Arabidopsis sequences as bait, we have identified 109 Citrus spp. EST clusters representing putative Citrus spp homologs to flowering-time genes. Some of these genes are required for the day length response, and some encode regulatory proteins specifically involved in the control of flowering, while others encode components of light signal transduction pathways or are involved in circadian clock function. A representation of the relationships among these processes is shown in Figure 1 and the putative homologs of the key players in Citrus spp are presented in Table 1. The role of each of these elements in the flowering-time pathways and their implication for the understanding of Citrus spp flowering processes are presented in the Discussion section.

Two genes play a prominent role at the "bottom" of the flowering promotion cascades: CONSTANS $(C O)$ and FLOWERING LOCUS C (FLC). The FLC gene is the point of convergence of the autonomous and vernalization pathways (Figure 1). Ultimately and in part through CONSTANS (CO) and FLC, the flowering signals lead to the induction of a set of genes called floral meristem identity (FMI) genes and responsible for the fate change of the meristems emerging on the flanks of the shoot apex (Long and Barton, 2000). This group of genes includes the $L E A F Y$ $(L F Y)$ gene, expressed in early floral stages and responsible for their floral fate (Lohmann and Weigel, 2002). We could not find any putative homolog to LFY in the CitEST database, but Citrus homologs to this gene have already been identified (Pena et al., 2001), thus indicating an underrepresentation of flowering-time sequences in the CitEST dataset.

The $C O$ gene is probably the most downstream actor, specific for the photoperiod pathway (Figure 1) and both the light and the internal clock precisely regulate $\mathrm{CO}$ protein accumulation (Valverde et al., 2004). Due to their importance to the regulation of flowering-time, the CO-like sequences found in the CitEST database were studied in greater detail and these results are presented separately in a separate section below.

\section{Elements of the Citrus CONSTANS-like gene family}

We have identified a total of 244 Citrus spp EST sequences showing significant (e-value lower than e- ${ }^{10}$ ) similarity to the Arabidopsis CO-like (COL) genes, by means of a combination of BLAST algorithms and keyword searches in the CitEST database (Table 2). When submitted to the CAP3 algorithm, these sequences were initially organized into 75 clusters. With further comparison of their deduced amino acid sequences, the number of valid clusters was reduced to 27.

Based on previous studies on Eucalyptus (Dornelas and Rodriguez, 2005) and sugarcane (Dornelas and Rodriguez, 2006) COL proteins, we concluded that this gene family evolves rapidly, particularly in the middle regions (see also Lagercrantz and Axelsson, 2000). Thus our analysis focused on the B-box sequences only and we excluded putative homologs to the related Arabidopsis STO (SALT TOLERANCE) gene. STO-like genes have B-boxes but no CCT domain. Additionally, we excluded the related ZIM gene from our analysis, which contains an additional ZIM motif. This short motif is found in a variety of plant transcription factors that contain GATA domains and its conserved amino acids form the pattern TIFF/YXG (Lagercrantz and Axelsson, 2000; Griffiths et al., 2003). We thus restricted our analysis to Citrus spp sequences showing the conserved B-box and CCT domains, according to the definition of the COL family provided by Griffiths et al. (2003). These assumptions explain the reduced number of

Table 2 - Citrus putative homologs to the CONSTANS-like genes of Arabidopsis.

\begin{tabular}{llll}
\hline Species & $\begin{array}{c}\text { Number of } \\
\text { ESTs }^{\mathrm{a}}\end{array}$ & Clusters $^{\mathrm{b}}$ & $\begin{array}{c}\text { Putative } \\
\text { homologs }^{\mathrm{c}}\end{array}$ \\
\hline Citrus aurantifolia & 14 & 8 & 4 \\
Citrus aurantium & 12 & 7 & 3 \\
Citrus latifolia & 5 & 3 & 0 \\
Citrus limonia & 5 & 3 & 1 \\
Citrus reticulata & 49 & 18 & 7 \\
Citrus sinensis & 130 & 23 & 7 \\
Poncirus trifoliata & 29 & 13 & 5 \\
\hline
\end{tabular}

${ }^{a}$ When using the BLASTp algorithm (Altschul et al., 1997) and considering an e-value of $\mathrm{e}^{-10}$. All Arabidopsis CO-like proteins were used as alternative bait sequences.

${ }^{b}$ Number of clusters formed by the given number of ESTs when using CAP3 assembling algorithm (Huang and Madan, 1999).

${ }^{\mathrm{C}}$ Number of clusters, after eliminating redundancy and after parsimony analysis. 
true putative Citrus spp homologs of COL members shown in Table 2.

As most of the CCT domain sequences are not available for the Citrus spp COL proteins, we produced alignments of the predicted peptides of the conserved B-box region for all Arabidopsis AtCO and AtCOL proteins and their putative Citrus spp homologs (Figure 2A).

Variation within the B-box domain suggested that the $\mathrm{CO}$-like genes could be further subdivided. To further examine the relationship between the putative Citrus spp COL homologs and their Arabidopsis counterparts in more detail, the sequence alignment shown in Figure 2A was used to determine genetic distances and to construct phylogenetic trees. Therefore, neighbor-joining (Figure 2B) and maximum parsimony trees (data not shown) were constructed, giving similar results. The proteins were consistently grouped into three principal clades (Figure 2B). These three groups were identified previously and are thought to have evolved prior to the divergence of monocots and dicots (Griffiths et al., 2003; Dornelas and Rodriguez, 2005; 2006). Group III genes comprised Arabidopsis and Citrus spp proteins with two zinc finger domains, the second of which was diverged from the CO-type B-box. Group II genes comprised Arabidopsis and Citrus spp proteins with a single B-box. Group I comprised the most $\mathrm{CO}$-like genes and included Citrus spp putative $\mathrm{CO}$ ortologs. Sequence comparisons showed that the clusters CS00-C1-100-086-A06, CL06-C4-501-017-G07, CG32C1-003-018-D09, CA26-C1-002-061-D07 and LT33-C1003-096-C01 presented significant similarity (e-value lower than $\mathrm{e}^{-10}$ ) to CO (Table 1), but only CS00-C1-100086-A06, CG32-C1-003-018-D09, and PT11-C1-901085-G05 had complete B-box sequences; and thus only these were considered for the phylogenetic analysis. All these three Citrus spp sequences were consistently maintained in the same cluster together with AtCO (Figure 2B).

There were subdivisions within Group I, but these had low bootstrap values (Figure 2B). CS00-C1-100-038C06 and CR05-C1-103-024-B09 had the most diverged B-Box domain of the Citrus spp genes and the phylogenetic analysis placed them, together with PT11-C1-901-054A04 and CR05C3-701-033-C01, on the same clade of the related Arabidopsis proteins AtCOL16 and AtCOL6-8, within Group II.

\section{Discussion}

\section{The flowering pathway regulated by gibberellins}

Because of the importance of crop load, methods for reducing the extent of biennial bearing in Citrus have been investigated for use in commercial production. Winter sprays with gibberellic acid (GA) are one management tool that can be used to regulate flowering, and minimize the effect of biennial bearing. In Citrus, as in many other perennial crops, GA application during bud development can inhibit flower production (Monselise and Halevy 1964; Guardiola et al., 1982; Lord and Eckard, 1987), and in the following spring lead to a greater proportion of single terminal flowers on leafy shoots, which tend to produce the larger fruits. On the other hand, in many annual plants such as Arabidopsis, GA has a promoting effect on flowering. Thus, either GA has contrasting roles in the flowering of different species, or abnormally high GA levels in woody perennials such as Citrus, but not in annuals such as Arabidopsis. This prevents normal flower formation, presumably by disrupting essential developmental events.

The Arabidopsis gal biosynthetic mutant flowers extremely late (sometimes never) in SD (Blazquez et al., 1998; Wilson et al., 1992). GA acts, at least in part, by upregulating the $L E A F Y(L F Y)$ gene. $L F Y$ expression is dramatically reduced in gal mutant in short days and constitutive expression of $L F Y$ is sufficient to rescue the late flowering of this mutant (Blazquez et al., 1998). A ciselement has been found in the $L F Y$ promoter that abolishes its response to GA without affecting $L F Y$ induction by photoperiod, indicating that the two different pathways are integrated at the level of $L F Y$ promoter (Blazquez and Weigel, 2000). GA is also involved in inducing SOC1 expression (Moon et al., 2003) and may also be the FLOWERING TIME (FT) gene. We have found Citrus putative homologs for $S O C 1$ and $F T$, but no clear homolog sequences to $L F Y$ were found within the CitEST database. Nevertheless, it is clear that the Citrus genome contains orthologs to $L F Y$ (Pena et al., 2001; Pillitteri et al., 2004). Accordingly, overexpressing the Arabidopsis LFY sequence in transgenic Citrus plants dramatically altered the flowering behavior and the transgenic plants flowered in a few months rather than several years (Pena et al., 2001).

\section{Autonomous and vernalization pathways}

Plants require not only external (environmental) factors but also internal (developmental) factors to promote flowering. Although the ecotypes used in the laboratory of Arabidopsis thaliana flower earlier, many ecotypes flower very late or require a cold treatment, vernalization. The FRIGIDA (FRI) gene is responsible for the differences of the lateness of flowering among Arabidopsis ecotypes, as all known early-flowering ecotypes have mutations in the FRI gene (Johanson et al., 2000). The FRI codes for a protein with 619 amino acids that has coiled-coil domain in two positions (Johanson et al., 2000). No putative homolog could be assigned to FRI among the Citrus spp. EST clusters. The FRI protein is a positive regulator of the Flowering Locus $C$ gene, which is a repressor for flowering (Michaels and Amasino, 1999). The FLC gene encodes a MADS-box protein (Michaels and Amasino, 1999; Peacock and Dennis, 1999). Despite the fact that no FRI homo$\log$ could be found among Citrus ESTs, we found putative homologs to FLC in six Citrus species (Table 1). Additionally, no sequence was found within the CitEST data set 

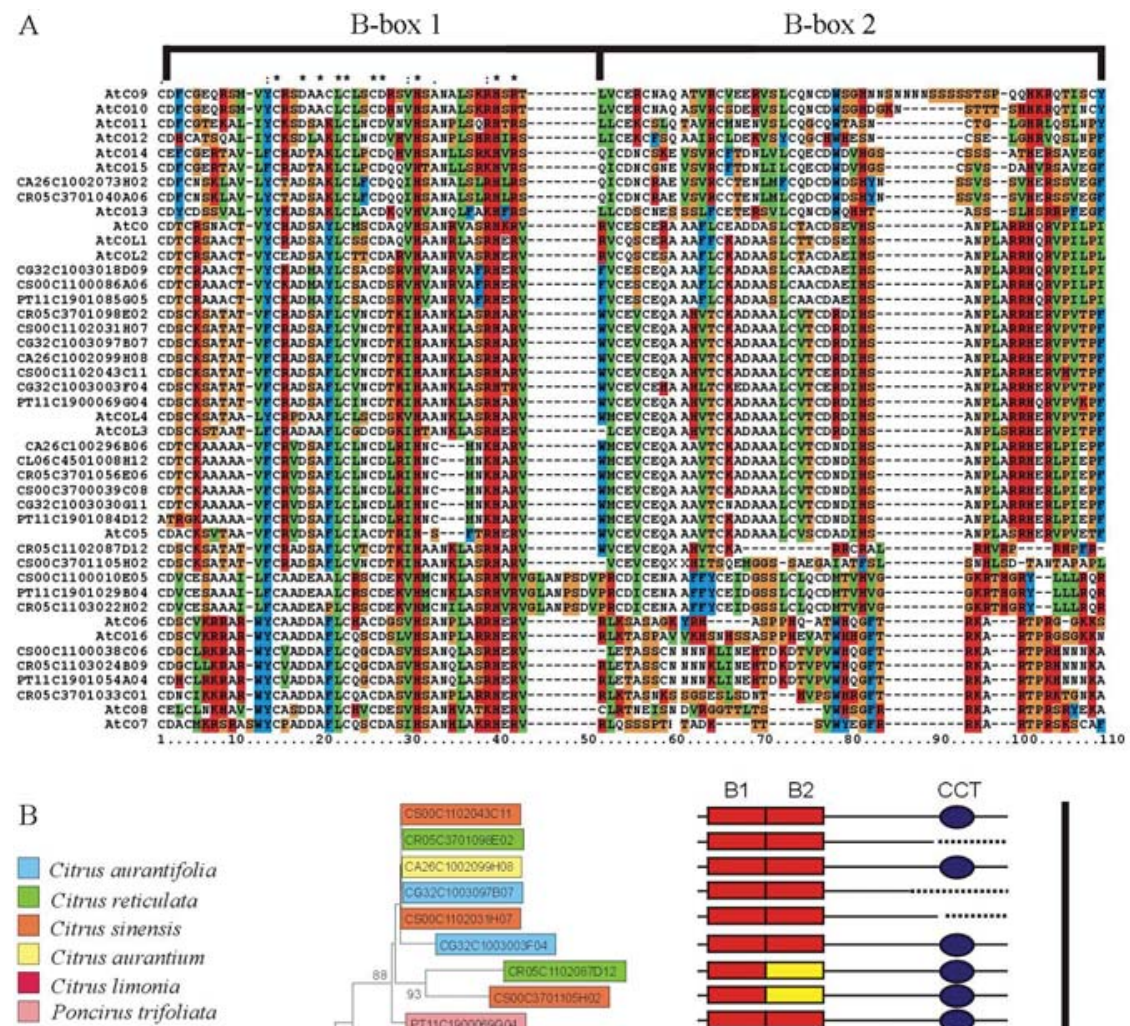

ma
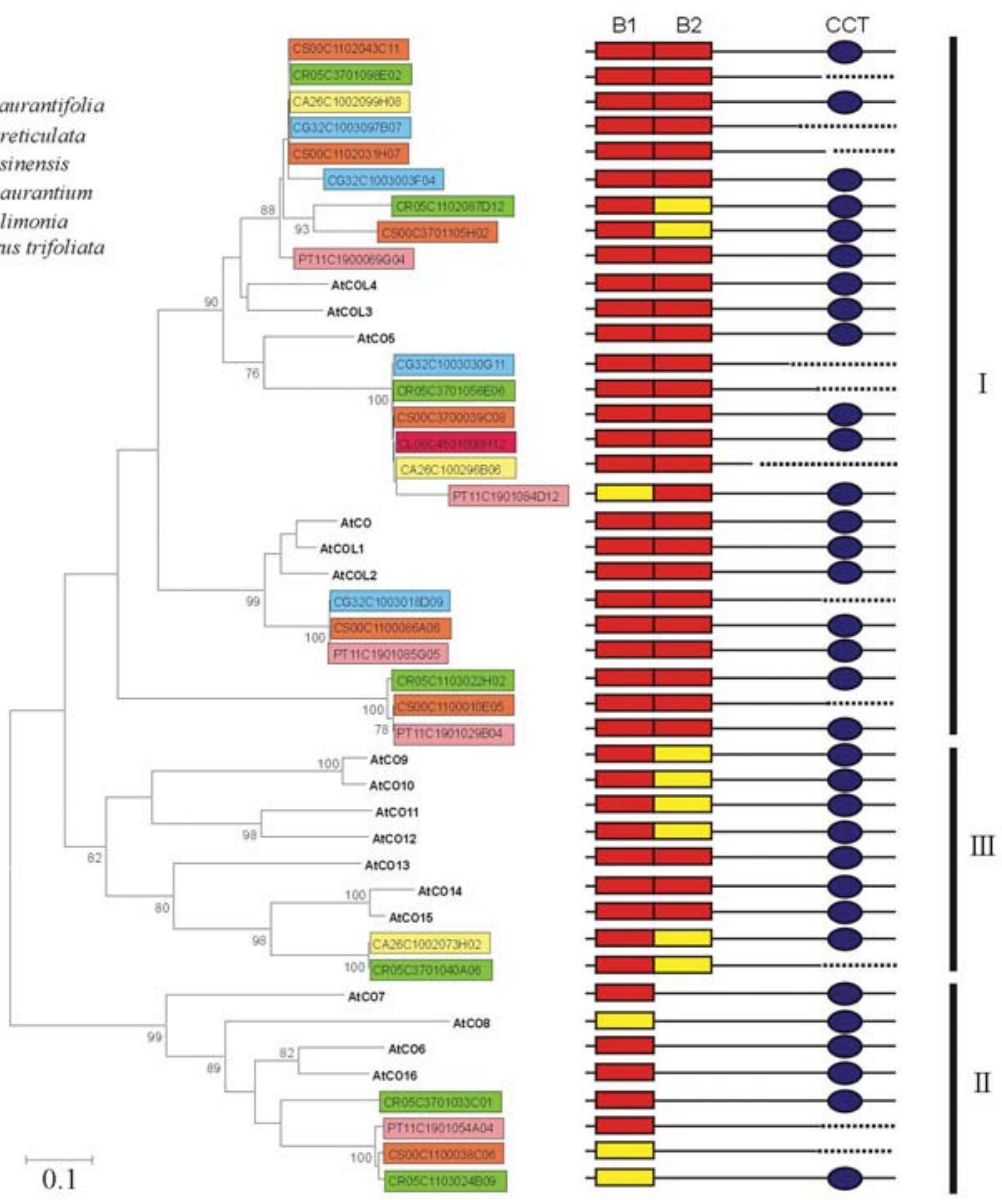

Figure 2 - Characterization of the putative CONSTANS gene family in Citrus. A. Alignment of predicted peptides of Citrus CO-like putative homologs and related genes from Arabidopsis. The region of the proteins aligned corresponds to the conserved B-box domains of the CO-like family (Robson et al., 2001; Griffiths et al., 2003). Amino acid colors are default of CLUSTAL software. B. Phylogenetic analysis of CO-like genes. A Neighbour-Joining tree was built based on the of B-box domain alignment shown in A. The Citrus deduced protein names are given in colored boxes. Genetic distances are shown at the given scale. Bootstrap values from 1,000 replicates were used to assess the robustness of the trees. Only bootstrap values above $75 \%$ are shown. The domain structures of each protein is also shown to the right side of their names. B1 and B2 are CO-like B-boxes (white rectangles) or derived zinc finger domains (solid rectangles). CCT is the conserved CCT carboxy-terminus domain (Robson et al., 2001). The dotted lines represent incomplete sequences. Arabidopsis MIPS codes are as follows: AtCO (At5g15840); AtCOL1 (At5g15850); AtCOL2 (At3g02380); AtCOL3 (At2g24790); AtCOL4 (At5g24930); AtCOL5 (At5g57660); AtCOL6 (At1g68520); AtCOL7 (At1g73870); AtCOL8 (At1g49130); AtCOL9 (At3g07650); AtCOL10 (AB023039); AtCOL11 (At4g15250); AtCOL12 (At3g21880); AtCOL13 (At2g47890); AtCOL14 (At2g33500); AtCOL15 (At1g28050); AtCOL16 (At1g25440). 
that would code for the other elements of the vernalization pathway: VRN1 and VRN2 (Chandler et al., 1996) or for the $V I P 1-7$ genes. VRN2 has a repressible role over the expression of FLC and codes for a protein with homology to PcG proteins (Sheldon et al., 2000). VIP4 was cloned and encodes another PcG protein (Zhang and van Nocker, 2002), and is a repressor of the $F L C$ gene as well. These results indicate that the autonomous branch of the vernalization pathway may be present, in Citrus, but that the connection with cold-sensing may have been lost during evolution. One strong argument in favor of this speculation is that the elements of the vernalization pathway have not been found in any tropical plant for which genomic resources are available including rice, for which the genome is completely sequenced (Izawa et al., 2003), Eucalyptus (Dornelas and Rodriguez, 2005) and sugarcane (Dornelas and Rodriguez, 2006).

\section{Light-dependent pathway and the role of CONSTANS-like proteins}

Red light is accepted by phytochrome proteins, which are encoded by PHYA through $E$ genes in Arabidopsis (Reed et al., 1993; Briggs et al., 2001; Ohto et al., 2001). We found putative Citrus spp homologs to PHYA, PHYB and PHYC, but similar to what was observed for other woody species (Dornelas and Rodriguez, 2005), we were not able to find significant similarities among Arabidospsis PHYD and PHYE within the CitEST data set (Table 1).

Blue light receptors are named as cryptochrome proteins, which are encoded by CRY1 and CRY2 in Arabidopsis (Ahmad and Cashmore, 1993; Lin et al., 1998). We found a putative homolog to CRY2 only among C. reticulata sequences, but CRY1 homologs could be found in five different Citrus species (Table 1). Arabidopsis cryptochrome gene $C R Y 1$ cooperatively functions with the $C R Y 2$ gene to repress the function of $C O$ and GIGANTEA (GI) (Mockler et al., 1999).

The functions of genes $L H Y, C C A 1, E L F 3$, and $T O C 1$ are related to the circadian clock that processes the light signals and converts them into periodic information (Hicks et al., 2001; Doyle et al., 2002). The processed signal is transmitted to the GI gene, whose product activates the $C O$ gene (Suarez-Lopez et al., 2001). Citrus spp putative homologs to all these circadian clock elements were found (Table 1), suggesting that the molecular elements of the circadian clock may be conserved among herbaceous and woody plants, despite their divergent reproductive behavior. This has also been observed for other woody species such as Eucalyptus (Dornelas and Rodriguez, 2005). These results thus indicate that the observed differences in the reproductive development between herbaceous and woody plants are likely to be the product of different interactions among clock elements rather than differences in the clock components themselves.
We have paid special attention to the characterization of the putative Citrus spp homologs to the Arabidopsis CO-like family members. The $\mathrm{CO}$ and $\mathrm{CO}$-like genes encode nuclear zinc finger-containing proteins, suggesting potential transcription factor function, but the precise mechanism of $\mathrm{CO}$ action is not yet understood (Parcy, 2005). In particular, CO has not been shown to bind DNA and is, therefore, assumed to be tethered to regulatory sequences through interaction with other transcription factors (Hepworth et al., 2002). Recently, evidence has accumulated indicating that CCAAT binding factors can mediate interactions between CONSTANS-like proteins and DNA (Ben-Naim et al., 2006). The members of the CO-family are very conserved and can be found among diverse angiosperm species and even in Physcomitrella (Zobell et al., 2005), suggesting that the function of these proteins in controlling reproductive development may be conserved as well.

The precise analysis of $\mathrm{CO}$ expression pattern has recently led to new and exciting questions regarding $\mathrm{CO}$ mode of action (Takada and Goto, 2003; An et al., 2004). Indeed, the photoperiodic signal was known to be perceived in leaves and somehow transmitted to the apex by the unknown florigen signal (Zeevaart, 1976; Bernier et al., 1993; Colasanti and Sundaresan, 2000). The discovery that $\mathrm{CO}$ is expressed in the vascular system of the leaves (in the phloem companion cells) and induces $F T$ in this tissue, suggests that the florigen signal is downstream or at the same level as $C O$ (Takada and Goto, 2003; An et al., 2004). Expression of $C O$ from different promoters showed that $\mathrm{CO}$ triggers early flowering when expressed in the leaf phloem but not in the apex (An et al., 2004, Ayre and Turgeon, 2004). These experiments convincingly suggested that CO acts from the leaves and that the florigen is downstream of CO. Accordingly, all Citrus spp. contigs that showed significant similarity to $\mathrm{CO}$ (Table 1; Figure 2) are formed exclusively by leaf-derived ESTs (with the exception of a $C$. limonia EST, CL06-C4-501-017-G07, which is derived from root tissues). As opposed to $C O$, its target gene $F T$ can trigger early flowering when expressed either from the leaves or from the apex, suggesting either that FT itself is the florigen or that FT can induce the florigen synthesis both from leaves and the apex. Knowing that $\mathrm{CO}$ acts from the leaves to induce $F T$ also raises many questions about the induction of $S O C l$ and $L F Y$. In Arabidopsis, both $L F Y$ and $\mathrm{SOCl}$ expression increase at the apex during the floral transition $(S O C 1$ in the apex itself and $L F Y$ in the flower anlagen). To date, the function of other CO-like family members is largely unknown. Nevertheless, there is evidence that $\mathrm{COL}$ proteins may directly interact with $\mathrm{CO}$ to provide the correct control of flowering time mediated by light (Martin et al., 2004). It will be interesting to access the expression patterns of the different Citrus $\mathrm{CO}$-like family members to see if their transcription correlates with the transition to the reproductive phase. 


\section{Conclusions and Perspectives}

There are physical, chemical, and biological signals that contain information for the onset of flowering. The four known pathways that respond to these signals have been characterized in Arabidopsis and some herbaceous model plants. The genetic-based framework of these pathways in these model plants can now be assessed by molecularly cloning each member. This task is generally much more difficult and time-consuming in woody plants due to their extended life cycles. Here we present the initial construction of a genetic framework containing the molecular elements which putatively control the flowering pathways in seven different Citrus species. Precise characterization of the in situ expression patterns of all these Citrus spp putative flowering-time genes will be important to understanding their roles in the flowering process, opening the way for the manipulation of their expression patterns in the future. The function of these elements can now be tested in heterologous systems, such as Arabidopsis, via transgenic approaches. We believe our results will be a valuable source for future research on the control of flowering and of biennial fruit bearing patterns in Citrus.

\section{Acknowledgments}

We would like to thank Marcos Machado for coordinating our efforts on the analysis of the data generated by the CitEST Project. We also extend our thanks to Kleber M. Borges and Juliana M. de Souza for excellent technical skills in sequencing and finally $\mathrm{CNPq}$ and FAPESP (Brazil) for financial support.

\section{References}

Ahmad M and Cashmore AR (1993) HY4 gene of $A$. thaliana encodes a protein with characteristics of a blue-light photoreceptor. Nature 366:162-166.

Altschul SF, Madden TL, Schäffer AA, Zhang J, Zhang Z, Miller W and Lipman DJ (1997) Gapped BLAST and PSI-BLAST: A new generation of protein database search programs. Nucleic Acids Res 25:3389-3402.

Amasino R (2004) Vernalization, competence, and the epigenetic memory of winter. Plant Cell 16:2553-2559.

An H, Roussot C, Suarez-Lopez P, Corbesier L, Vincent C, Pineiro M, Heptworth S, Mouradov A, Justin S, Turnbull C, et al. (2004) CONSTANS acts in the phloem to regulate a systemic signal that induces photoperiodic flowering of Arabidopsis. Development 131:3615-3626.

Araki T (2001) Transition from vegetative to reproductive phase. Curr Opin Plant Biol 4:63-68.

Ayre BG and Turgeon R (2004) Graft transmission of a floral stimulant derived from CONSTANS. Plant Physiol 135:2271-2278.

Bastow R and Dean C (2003) Plant sciences. Deciding when to flower. Science 302:1695-1696.

Ben-Naim O, Eshed R, Parnis A, Teper-Bamnolker P, Shalit A, Coupland G, Samach A and Lifschitz E (2006) The CCAAT binding factor can mediate interactions between CONSTANS-like proteins and DNA. Plant J 46:462-476.

Bernier G, Havelange A, Houssa C, Petitjean A and Lejeune P (1993) Physiological signals that induce flowering. Plant Cell 5:1147-1155.

Blazquez MA and Weigel D (2000) Integration of floral inductive signals in Arabidopsis. Nature 404:889-892.

Blazquez MA, Green R, Nilsson O, Sussman MR and Weigel D (1998) Gibberelins promote flowering of Arabidopsis by activating the LEAFY promoter. Plant Cell 10:791-800.

Boss PK, Vivier M, Matsumoto S, Dry IB and Thomas MR (2001) A cDNA from grapevine (Vitis vinifera L.), which shows homology to AGAMOUS and SHATTERPROOF, is not only expressed in flowers but also throughout berry development. Plant Mol Biol 45:541-553.

Boss PK, Sensi E, Hua C, Davies C and Thomas MR (2002) Cloning and characterization of grapevine (Vitis vinifera L.) MADS-box genes expressed during inflorescence and berry development. Plant Sci 162:887-895.

Boss PK, Bastow RM, Mylne JS and Dean C (2004) Multiple pathways in the decision to flower: Enabling, promoting, and resetting. Plant Cell 16 Suppl:S18-S31.

Briggs WR, Beck CF, Cashmore AR, Christie JM, Hughes J, Jarillo JA, Kagawa T, Kanegae H, Liscum E and Nagatani A (2001) The phototropin family of photoreceptors. Plant Cell 13:993-997.

Chandler J, Wilson A and Dean C (1996) Arabidopsis mutants showing an altered response to vernalization. Plant $\mathrm{J}$ 10:637-644.

Colasanti J and Sundaresan V (2000) 'Florigen' enters the molecular age: Long-distance signals that cause plants to flower. Trends Biochem Sci 25:236-240.

Dornelas MC and Rodriguez APM (2005) Identifying Eucalyptus expressed sequence tags related to Arabidopsis floweringtime pathway genes. Braz J Plant Physiol 17:255-266.

Dornelas MC and Rodriguez APM (2006) Evolutionary conservation of genes controlling flowering pathways between Arabidopsis and grasses. In: Teixeira da Silva JA (ed) Floriculture, Ornamental and Plant Biotechnology. v. 4. 1st edition. Global Science Books, London, pp 272-279.

Dornelas MC, Amaral WAN and Rodriguez APM (2004) EgLFY, the Eucalyptus grandis homolog of the Arabidopsis gene $L E A F Y$ is expressed in reproductive and vegetative tissues. Braz J Plant Physiol 16:105-114.

Doyle MR, Davis SJ, Bastow RM, McWatters HG, KozmaBognar L, Nagy F, Millar AJ and Amasino RM (2002) The ELF4 controls circadian rhythms and flowering time in Arabidopsis thaliana. Nature 419:74-77.

Garcia-Luis A and Kanduser M (1995) Changes in dormancy and sensitivity to vernalization in axillary buds of Satsuma mandarin examined in vitro during the annual cycle. Ann Bot 76:451-455.

Garcia-Luis A, Kanduser M, Santamarina P and Guardiola JL (1992) Low temperature influence on flowering in Citrus. The separation of inductive and bud dormancy releasing effects. Physiol Plant 86:648-652.

Garcia-Luis A, Kanduser M and Guardiola JL (1995) The influence of fruiting on the bud sprouting and flower induction responses to chilling in Citrus. J Hort Sci 70:817-825. 
Griffiths S, Dunford RD, Coupland G and Laurie DA (2003) The evolution of the CONSTANS-like gene families in barley, rice and Arabidopsis. Plant Physiol 131:1855-1867.

Guardiola JL, Monerri C and Agusti M (1982) The inhibitory effect of gibberellic acid on flowering in Citrus. Physiol Plant 55:136-142.

Hall TA (1999) BioEdit: A user-friendly biological sequence alignment editor and analysis program for Windows 95/98/NT. Nucleic Acids Symp Ser 41:95-98.

Hepworth SR, Valverde F, Ravenscroft D, Mouradov A and Coupland G (2002) Antagonistic regulation of flowering-time gene SOC1 by CONSTANS and FLC via separate promoter motifs. Embo J 21:4327-4337.

Hicks KA, Albertson TM and Wagner DR (2001) EARLY FLOWERING3 encodes a novel protein that regulates circadian clock function and flowering in Arabidopsis. Plant Cell 13:1281-1292.

Huang X and Madan A (1999) CAP3: A DNA sequence assembly program. Genome Res 9:868-877.

Izawa T, Takahashi Y and Yano M (2003) Comparative biology comes into bloom: Genomic and genetic comparison of flowering pathways in rice and Arabidopsis. Curr Opin Plant Biol 6:113-120.

Johanson U, West J, Lister C, Michaels S, Amasino R and Dean C (2000) Molecular analysis of FRIGIDA, a major determinant of natural variation in Arabidopsis flowering time. Science 290:344-347.

Koltunow AM, Smith AV and Sykes SR (2000) Molecular and conventional breeding strategies for seedless Citrus. Acta Hort 535:169-174.

Kotoda N, Wada M, Komori S, Kidou S, Abe K, Masuda T and Soejima J (2000) Expression pattern of homologues of floral meristem identity genes $L F Y$ and $A P 1$ during flower development in apple. J Amer Soc Hort Sci 125:398-403.

Krajewski AJ and Rabe E (1995) Citrus flowering: A critical evaluation. J Hort Sci 70:357-374.

Kyozuka J, Harcourt R, Peacock WJ and Dennis ES (1997). Eucalyptus has functional equivalents of the Arabidopsis AP1 gene. Plant Mol Biol 35:573-584.

Lagercrantz U and Axelsson T (2000) Rapid evolution of the family of CONSTANS like genes in plants. Mol Biol Evol 17:1499-1507.

Lin C, Yang H, Guo H, Mockler T, Chen J and Cashmore AR (1998) Enhancement of the blue-light sensitivity of Arabidopsis young seedlings by a blue-light receptor cry 2 . Proc Natl Acad Sci USA 95:2686-2690.

Lohmann JU and Weigel D (2002) Building beauty: The genetic control of floral patterning. Dev Cell 2:135-142.

Long J and Barton MK (2000) Initiation of axillary and floral meristems in Arabidopsis. Dev Biol 218:341-353.

Lord EM and Eckard KJ (1987) Shoot development in Citrus sinensis L. (Washington navel orange). II. Alteration of developmental fate of flowering shoots after GA3 treatment. Bot Gaz 148:17-22.

Marchler-Bauer A, Anderson JB, Cherukuri PF, DeWeese-Scott C, Geer LY, Gwadz M, He S, Hurwitz DI, Jackson JD and Ke Z (2005) CDD: A Conserved Domain Database for protein classification. Nucleic Acids Res 33:192-196.

Martin J, Storgaard M, Andersen CH and Nielsen KK (2004) Photoperiodic regulation of flowering in perennial ryegrass involving a CONSTANS-like homolog. Plant Mol Biol 56:159-169.

Michaels SD and Amasino RM (1999) FLOWERING LOCUS C encodes a novel MADS domain protein that acts as a repressor of flowering. Plant Cell 11:949-956.

Mockler TH, Guo H, Yang H, Duong H and Lin C (1999) Antagonistic actions of Arabidopsis cryptochromes and phytochrome $\mathrm{B}$ in the regulation of floral induction. Development 126:2073-2082.

Monselise SP and Halevy AH (1964) Chemical inhibition and promotion of citrus flower bud induction. Am Soc Hort Sci 84:141-146.

Moon Y-H, Chen L, Pan RL, Chang J-S, Zhu T, Maffeo DM and Sung ZR (2003) EMF genes maintain vegetative development by repressing the flower program in Arabidopsis. Plant Cell 15:681-693.

Mouradov A, Cremer F and Coupland G (2002) Control of flowering time: Interacting pathways as a basis for diversity. Plant Cell Supplement:S11-S130.

Ohto M, Onai K, Furukawa Y, Aoki E, Araki T and Nakamura K (2001) Effects of sugar on vegetative development and floral transition in Arabidopsis. Plant Physiol 127:252-261.

Parcy F (2005) Flowering: A time for integration. Int J Dev Biol 49:585-593.

Peacock WJ and Dennis ES (1999) The FLF MADS box gene: A repressor of flowering in Arabidopsis regulated by vernalization and methylation. Plant Cell 11:445-458.

Pena L, Martin-Trillo M, Juarez J, Pina JA, Navarro L and Martinez-Zapater JM (2001) Constitutive expression of Arabidopsis LEAFY or APETALA1 genes in citrus reduces their generation time. Nat Biotech 19:263-267.

Pillitteri LJ, Lovatt CJ and Walling LL (2004) Isolation and characterization of $L E A F Y$ and APETALA1 homologues from Citrus sinensis L. Osbeck 'Washington'. J Amer Soc Hort Sci 129:846-856.

Putterill J, Robson F, Lee K, Simon R and Coupland G (1995) The CONSTANS gene of Arabidopsis promotes flowering and encodes a protein showing similarities to zinc finger transcription factors. Cell 80:847-857.

Reed JW, Nagpal P, Poole DS, Furuya M and Chory J (1993) Mutations in the gene for the red/far-red light receptor phytochrome B alter cell elongation and physiological responses throughout Arabidopsis development. Plant Cell 5:147-157.

Robson F, Costa MMR, Hepworth S, Vizir I, Pineiro M, Reeves PH, Putterill J and Coupland G (2001) Functional importance of conserved domains in the flowering-time gene CONSTANS demonstrated by analysis of mutant alleles and transgenic plants. Plant J 28:619-631.

Saitou N and Nei M (1987) The neighbour joining method: A new method for reconstructing phylogenetic trees. Mol Biol Evol 4:406-425.

Sheldon CC, Rouse DT, Finnegan EJ, Peacock WJ and Dennis ES (2000) The molecular basis of vernalization: The central role of FLOWERING LOCUS C (FLC). Proc Natl Acad Sci USA 97:3753-3758.

Simpson GG and Dean C (2002) Arabidopsis, the Rosetta stone of flowering time? Science 296:285-289.

Simpson GG, Gendall AR and Dean C (1999) When to switch to flowering. Annu Rev Cell Dev Biol 15:519-550.

Southerton SG, Strauss SH, Olive MR, Harcourt RL, Decroocq V, Zhu X, Llewellyn DJ, Peacock WJ and Dennis ES (1998) 
Eucalyptus has a functional equivalent of the Arabidopsis floral meristem identity gene $L E A F Y$. Plant Mol Biol 37:897-910.

Suarez-Lopez P, Wheatley K, Robson F, Onouchi H, Valverde F and Coupland G (2001) CONSTANS mediates between the circadian clock and the control of flowering in Arabidopsis thaliana. Nature 410:1116-1120.

Sung SK, Yu GH and An G (1999) Characterization of MdMADS2, a member of the SQUAMOSA subfamily of genes, in apple. Plant Physiol 120:969-978.

Sung SK, Yu GH, Nam J, Jeong DH and An G (2000) Developmentally regulated expression of two MADS-box genes, MdMADS3 and MdMADS4, in the morphogenesis of flower buds and fruits in apple. Planta 210:519-528.

Takada S and Goto K (2003) TERMINAL FLOWER2, an Arabidopsis homolog of HETEROCHROMATIN PROTEIN1, counteracts the activation of FLOWERING LOCUS T by CONSTANS in the vascular tissues of leaves to regulate flowering time. Plant Cell 15:2856-2865.

Thompson JD, Higgins DG and Gibson TJ (1994) CLUSTAL W: Improving the sensitivity of progressive multiple sequence alignment through sequence weighting, positions-specific gap penalties and weight matrix choice. Nucleic Acids Res 22:4673-4680.

Valverde F, Mouradov A, Soppe W, Ravenscroft D, Samach A and Coupland G (2004) Photoreceptor regulation of
CONSTANS protein in photoperiodic flowering. Science 303:1003-1006.

Wilson RN, Heckman JW and Somerville CR (1992) Gibberelin is required for flowering in Arabidopsis thaliana under short days. Plant Physiol 100:403-408.

Yao J-L, Dong Y-H, Kvarnheden A and Morris B (1999) Seven MADS-box genes in apple are expressed in different parts of the fruit. J Amer Soc Hort Sci 124:8-13.

Zeevaart JAD (1976) Physiology of flower formation. Annu Rev Plant Physiol 27:321-348.

Zhang H and van Nocker S (2002) The VERNALIZATION 4 gene encodes a novel regulator of FLOWERING LOCUS C. Plant J 31:663-667.

Zobell O, Coupland G and Reiss B (2005) The family of CONSTANS-like genes in Physcomitrella patens. Plant Biol 7:266-275.

\section{Internet Resources}

CitEST Database, http://citest.centrodecitricultura.br/ (March 25, 2006).

NCBI, http://www.ncbi.nlm.nih.gov/ (March 25, 2006).

BLAST, http://www.ncbi.nlm.nih.gov/BLAST/ (March 25, 2006).

MEGA software, http://www.megasoftware.net (March 3, 2006). Associate Editor: Alessandra Alves de Souza 